tion spectroscopy. X-ray photoelectron spectroscopy has been used to quantify very low concentrations of dopants (below $1 \%$ in weight). The ISO TC229 has made great progress on standardizing these tools.

On the development of new metrology tools, various optical techniques provide fast and noninvasive methods. While optical absorption and Raman spectroscopy can already be considered standard methods, new techniques are pushing the limits, such as tip-enhanced Raman spectroscopy, nonlinear optics, plasmonics, and photocurrent spectroscopy. Graphene, again, was discussed because the use of isotope metrology on this material allowed the identification of the signal from specific layers in a multilayer sample and enhanced the understanding of the structure and properties of graphite intercalation compounds.
Overall, the nanotube field needs further development from a metrology standpoint. Further work is needed to speed the development of metrology, especially with regard to the application of carbon nanotube materials in biology, medicine, and issues related to toxicology.

Ado Jorio,

Universidade Federal de Minas Gerais, Brazil

\title{
Bilateral Energy Conference to be held in France in 2014
}

www.emrs-strasbourg.com

T he Bilateral Energy Conference, held jointly by the Materials Research Society (MRS) and the European Materials Research Society (E-MRS,) will be included as part of the 2014 E-MRS Spring Meeting in Lille, France, on May 26-30. The conference chairs are Hans Richter of Gesellschaft zur Förderung von Wissenschaft und Wirtschaft, Germany, and William Tumas of the National Renewable Energy Laboratory, USA.

The symposia topics are:

- Materials research for group IV semiconductors: growth, characterization and technological developments

- Advanced materials and characterization techniques for solar cells II

- Materials development for solar fuel production and energy conversion
- Organic/polymer and hybrid photovoltaics

- Materials by design for energy applications through theory and experiment

- Materials for electrochemical energy conversion - from modular to largescale energy generation and storage

- Crystals for energy conversion and storage (jointly organized with the International Organization for Crystal Growth)

The abstract deadline is January 16, 2014.

The E-MRS Spring Meeting also includes topics on materials for energy and environment; nanomaterials; materials and light; hybrid, organic, and bioma- terials; and crystal growth in materials science (with symposia jointly organized with the International Organization for Crystal Growth), with the January 16, 2014 deadline for abstracts. This Meeting - chaired by Ian W. Boyd (University of Brunel, UK), Gilles Dennler (IMRA Europe, France), Roberto M. Faria (University of São Paulo, Brazil), Roberto Fornari (University of Parma, Italy), and Elvira Fortunato (FCT-UNL, Portugal) - also features a workshop on grand challenges in materials and a tutorial, on May 25, about analysis of radioactive nuclear materials.

For more information, access the EMRS website www.emrs-strasbourg.com.

\section{E-MRS call for nominations for 2014 EU-40 Materials Prize} www.emrs-strasbourg.com

T he European Materials Research Society (E-MRS) is accepting nominations for the 2014 EU-40 Materials Prize. This award is given to recognize outstanding contributions to materials research by a scientist under 40. The award is reserved for researchers showing exceptional promise as leaders in materials science, having performed the research for which this prize is awarded while working in Europe.

The award consists of a $€ 5000$ cash prize, a certificate, waiver of the meeting registration fee, and a plenary talk at the 2014 Spring Meeting of the European Materials Research Society (May 26-30, Congress Centre, Lille, France) where the award will be presented.

Nominations should include

- Curriculum Vitae including birth date;

- List of key publications (including citations and impact factors);

- Letters of support from two wellestablished scientists; and
- Any additional supporting information relevant to the award.

The nomination package should not exceed 10 pages (excluding the list of key publications) and should be sent by email to emrs@emrs-strasbourg. com (subject: eu40materials) before the January 31, 2014 deadline. The nominee shall not have reached his/her 40th birthday in the year in which the nomination is submitted. 